\title{
Sobre Verdad y Posverdad en sentido social
}

\author{
On Truth and Post-truth in a social sense
}

\author{
Agustín Sánchez Cotta, Universidad de Córdoba, Avda. Medina Azahara, 514071 \\ Córdoba, España. \\ I62sacoa@uco.es | Orcid: https://orcid.org/0000-0002-1655-7175
}

DOI: http://dx.doi.org/10.12795/Ambitos.2019.i45.13

\begin{abstract}
Resumen
El término posverdad fue acuñado recientemente debido a su alta frecuencia de aparición en los medios de comunicación. Su emergencia surge de la denuncia periodística ante los bulos, las noticias falsas, y a veces incluso las mentiras, en defensa de la veracidad informativa. Este artículo reseña el trabajo de Lee Mclntyre para proponer una definición de posverdad, enmarcándolo en un lugar concreto entre los límites de lo verdadero y lo falso. Dicha definición revela conflictos sociales en los discursos posverdaderos, al estructurar la realidad mediante ciertas opiniones, prejuicios, y creencias que la totalidad de la sociedad no comparte, al mismo tiempo que ignora hechos relevantes, proceso que el autor define como supremacía ideológica. En ese contexto, también se expone una refutación de la idea de verdad desde la filosofía de Nietzsche, cuya concepción inicial del término es cercana a la de Mclntyre, tal es el nexo de ambos desarrollos filosóficos. Ante la problemática mediática en la pérdida de lo verdadero, como instrumento para la distinción entre noticias reales y falsas, se argumentará que la filosofía nietzscheana resalta además
\end{abstract}


un valor de acuerdo social, inherente a la idea de verdad. Este nuevo y secundario aspecto revaloriza su idea e importancia frente a la falsedad. Mientras que las noticias falsas construirían una realidad aceptable tan solo por algunos, las verdaderas construyen una realidad aceptable por todos.

\begin{abstract}
The term post-truth has come to prominence recently due to its frequent use in the media. Its emergence comes from the journalistic defence of the truth through denouncing fake news, unfounded rumours, and lies propagated by some media sources. The following article draws on the work of Lee Mclntyre in order to propose a definition of post-truth, and frame it between the extremes of truth and falsehood. This definition reveals social conflicts in the post-truth discourse, which constructs a reality mediate by certain opinions, prejudices and beliefs that are not shared by society as a whole, while at the same time disregarding relevant facts - a process defined by McIntyre as 'ideological supremacy'. In this context, it is also argued here the refutation of the idea of truth drew from the philosophy of Nietzsche, whose first conception of that term is closed to the one used by Mclntyre as a frame reference for his post-truth definition, hence there is a link between both philosophical developments. Faced with the media's problem of the loss of truth as tool to distinguish between real news and fake news, it will be argued that Nietzschean philosophy also underlines the importance of social agreement inherent to the idea of truth. This new and secondary aspect revaluates the idea of truth against falsehood. While fake news creates a reality only acceptable for some, news based on the idea of 'social truth' create a reality acceptable to us all.
\end{abstract}

Palabras clave: Filosofía, Mentira, Posverdad, Verdad, Falsedad.

Keywords: Philosophy, Lie, Post-truth, truth, falsity.

\title{
1. INTRODUCCIÓN
}

En este artículo se expone una definición sobre el concepto de posverdad, y una reflexión sobre sus implicaciones en los campos de la verdad y la falsedad desde la filosofía, atendiendo a la referencial establecida por el diccionario Oxford, cuya institución además la denominó palabra del año en el 2016 (BBC News, 2016). La razón del galardón recibido está justificada en el crecimiento de uso en los medios de comunicación. Acudiendo a los datos (Mclntyre, 2018, p.1) expone que la presencia del término aumentó un dos mil por cien, en el contexto de dos eventos políticos: las elecciones de Estados Unidos y el Referéndum de Reino Unido de Brexit. Es evidente que, ante este fenómeno de propagación, el término ha adquirido una multiplicidad de significados y significantes, ello genera la necesidad de establecer posibles definiciones de las realidades que representa. En general, tales usos múltiples del 
término se han centrado en la denuncia, de ciertos medios de comunicación hacia otros, con acusaciones de la falta de rigor y veracidad, junto con el aumento de la propaganda y la manipulación en las redes de información. Esto implica que, desde un criterio de verdad, basado en una correcta interpretación de los datos y los hechos, se han condenado interpretaciones consideradas falsas. Es necesario contar con una definición más extensa de la idea de posverdad, incluyéndola en los ámbitos de la verdad y la falsedad, no solo por la extensión de uso, sino por el conflicto mediático.

\subsection{Estructura del texto, hipótesis de trabajo y metodología}

El artículo se estructura en los siguientes apartados. En primer lugar, se utiliza el reciente trabajo de Posverdad (Lee McIntyre, 2018), para abordar la tarea de precisar el concepto de posverdad, dentro de la teoría de la verdad, concretamente entre los campos epistemológicos de lo verdadero y lo falso, distinguiéndose entre verdad, falsedad, mentira, tontería y finalmente, posverdad. En segundo lugar, se expone una posible refutación de la idea de verdad, y por ende también de la falsedad, en los trabajos del primer periodo filosófico de Friedrich Nietzsche, aquí se descubre que el punto de partida del concepto de verdad en Nietzsche es muy cercano al que usa Mclntyre. Considerando la posibilidad de aceptar la argumentación refutadora de Nietzsche, en tercer lugar se revela que dicho discurso incluye un valor de cohesión social en la idea de verdad. En cuarto y último lugar se concluye que la posverdad implica una construcción de la realidad sesgada a solo ciertos sectores de la sociedad, mientras que la verdad, que ahora se definiría como 'verdad social', implica por el contrario una construcción de la realidad aceptada por la totalidad de la sociedad, con independencia de su veracidad. Se puede inferir de tal conclusión un criterio social para distinguir la verdad de la posverdad, frente a argumentaciones escépticas que refuten el primer término. Esto conllevaría la pervivencia de la verdad como instrumento para la distinción entre noticias falsas y noticias verdaderas.

La hipótesis con la que se trabaja consiste en definir la posverdad, distinguiéndola desde su concepto referente, la verdad, y ubicándola en el campo de la falsedad; al mismo tiempo se intenta dilucidar qué garantías tiene de permanecer ahí cuando la verdad es rebatida. Para trabajar esta hipótesis, nos es necesario contar con un concepto de verdad, cuyas características son el ser única, objetiva y absoluta en su concreta declaración; y si entendemos la posverdad como una subversión de esta, necesitamos por ende: un concepto de falsedad, un criterio para diferenciar entre verdad y falsedad, y un listado de tipos de falsedades hasta vislumbrar al menos el de la posverdad. Desde este punto, es necesario ofrecer un análisis de la refutación de la verdad, lo que llevaría a esta también al campo de la falsedad, luego nos quedaría entender si aún podemos distinguir entre la verdad rebatida, las falsedades y los discursos posverdaderos. 
La metodología usada ha consistido en el estudio de la obra de Lee Mclntyre, lo que ha permitido definir el concepto de posverdad, y su ubicación entre los campos de la verdad y la falsedad; posteriormente, se ha analizado el periodo temprano filosófico de Friedrich Nietzsche, donde el autor aborda la problemática de la verdad y la falsedad. Concretamente, el texto principal para este estudio ha sido Sobre verdad y mentira en sentido extramoral. (Nietzsche, 1872/1996). Para alcanzar una mejor perspectiva de dichas tesis, han sido relevantes las notas personales de Nietzsche que sirvieron para construir tal postura filosófica, a las cuales tenemos acceso recientemente a través de la publicación de los Fragmentos Póstumos (Meca, 2010). Las notas y las reflexiones de Nietzsche en torno a la idea de verdad también abarcan el periodo de confección de una de sus obras capitales: Humano, demasiado Humano (Nietzsche, 1878/2001), la cual se publicó tan solo unos años después, y por tanto también usaremos aquí. Estos trabajos pertenecen a su periodo crítico y negativo, él mismo lo denomina la "filosofía del martillo".

Posteriormente, se han establecidos paralelismos entre el concepto de verdad de Mclntyre y el concepto de verdad de Nietzsche. Finalmente, se ha reflexionado sobre cuál debería ser el criterio de separación entre verdad y posverdad, si aceptamos la refutación del primer concepto en filosofía de Nietzsche, y la definición del segundo en Mclntyre.

\subsection{Estado de la cuestión y actualidad bibliográfica sobre la posverdad}

Acudiendo a la definición del diccionario Oxford (2016), posverdad precisa aquellas maneras de interpretar la realidad donde los hechos importan menos que las opiniones, las emociones y las creencias. Esta definición presenta una contraposición entre dos interpretaciones fenoménicas: aquellas basadas en los hechos y los datos, y aquellas basadas en los factores subjetivos como son los sentimientos y los juicios personales, ignorando y transgrediendo tales bases fácticas. Luego como punto de partida, el término posverdad refiere al discurso en el que la objetividad pierde valor ante la subjetividad. La problemática de la posverdad surge en la hegemonía que discursos subjetivos pueden propagar a través de noticias falsas y bulos.

Existe una reciente explosión de publicaciones que tratan el concepto de posverdad y su relación con la verdad y la mentira desde la filosofía. Higgins (2016), por ejemplo, establece que la diferencia entre posverdad y mentira radica en el área donde la posverdad se ejerce: la política. Higgins insiste en que debido a la impunidad e influencia de sus agentes, la sociedad termina por aceptar el relato posverdadero sin reclamar el verdadero; también señala al relativismo epistémico, desarrollado en la filosofía, como fuente de la argumentación en contra de la verdad, que ha permitido el florecimiento de la información falsa. De la misma manera, Sepczynska (2019) ha concluido que la capacidad de reescribir la historia es la que distingue la mentira de la 
posverdad. En concreto, utilizando el marco teórico de política de Hanna Arendt, la autora recrimina la injerencia de la violencia discursiva en la política actual, lo cual describe con el término 'postpolítica'. Sepczynska considera que es el perfecto caldo de cultivo para motivar la manipulación en lugar del convencimiento.

La mayoría de los autores restantes enmarcan la cuestión de la posverdad dentro la filosofía política, en lugar de hacerlo dentro de la teoría de la verdad, como se aborda en esta investigación. También sería relevante destacar a Van Parijs (2018), quien considera que los nuevos relatos posverdaderos generan hostilidad dentro de nuestras sociedades liberales, mientras que ya habíamos aprendido a convivir en un marco político de respeto a relatos infundados en hechos (como son los religiosos). A una conclusión cercana se llegará en las líneas de este trabajo.

\section{REVISIÓN TEÓRICA Y PLANTEAMIENTO DEL PROBLEMA}

\subsection{Mclntyre. Caminando de la verdad a la posverdad}

En su trabajo sobre el discurso posverdadero, Mclntyre (2018) comienza acudiendo a una definición de verdad que sirva de referente ante una definición de lo posverdadero. Desde su estudio sobre el tema, la mejor definición de verdad es la establecida por Aristóteles, la cual defiende una correspondencia entre aquello que decimos y aquello a lo que nos referimos (p.7). En términos lógicos, decir que $P$ es $P$, $y \neg P$ es $\neg P$ es verdadero, mientras que decir que $P$ es $\neg P$ y $\neg P$ es $P$, es falso. Con un ejemplo preciso: decir que una silla es una silla es verdadero, decir que lo que no es una silla no es una silla, también es verdadero; por el contrario llamar silla a lo que no es una silla, es falso, y decir que no es una silla a una silla, también es falso. Luego la verdad está en la correcta correspondencia entre un término y el objeto que designa en la realidad, en la relación establecida entre la palabra y la cosa. Una correspondencia correcta es una verdad y una incorrecta es una falsedad.

Partiendo de esa tesis, el autor reconoce que, mientras la verdad es como tal un concepto único, fijo, inmutable, y absoluto (dado que cualquier ausencia de estas característica negaría su esencia de verdad); la falsedad es un campo de conceptos múltiples, un nicho de términos donde se incluyen los siguientes: la falsedad en sí, la ignorancia, la tontería y la mentira (McIntyre, 2018, p. 8-9). La diferencia entre estos casos está en el grado de responsabilidad moral. En la falsedad la responsabilidad es nula, se declara como verdadero algo falso con desconocimiento. La ignorancia es un tipo de falsedad con cierta responsabilidad, se declara como verdadero algo falso, pero se podría haber investigado la verdad. En la tontería la responsabilidad aumenta un nuevo grado dado que, por primera vez, se conoce la falsedad de la declaración, pero se es indiferente a ella. Por último, el mayor grado de responsabilidad surge en la mentira, donde tenemos una intención de engaño, un deseo de manipular la verdad y 
de falsificar la lectura de los hechos. La falsedad y todos estos casos tienen en cambio una característica común: funcionan ante la ausencia de la verdad.

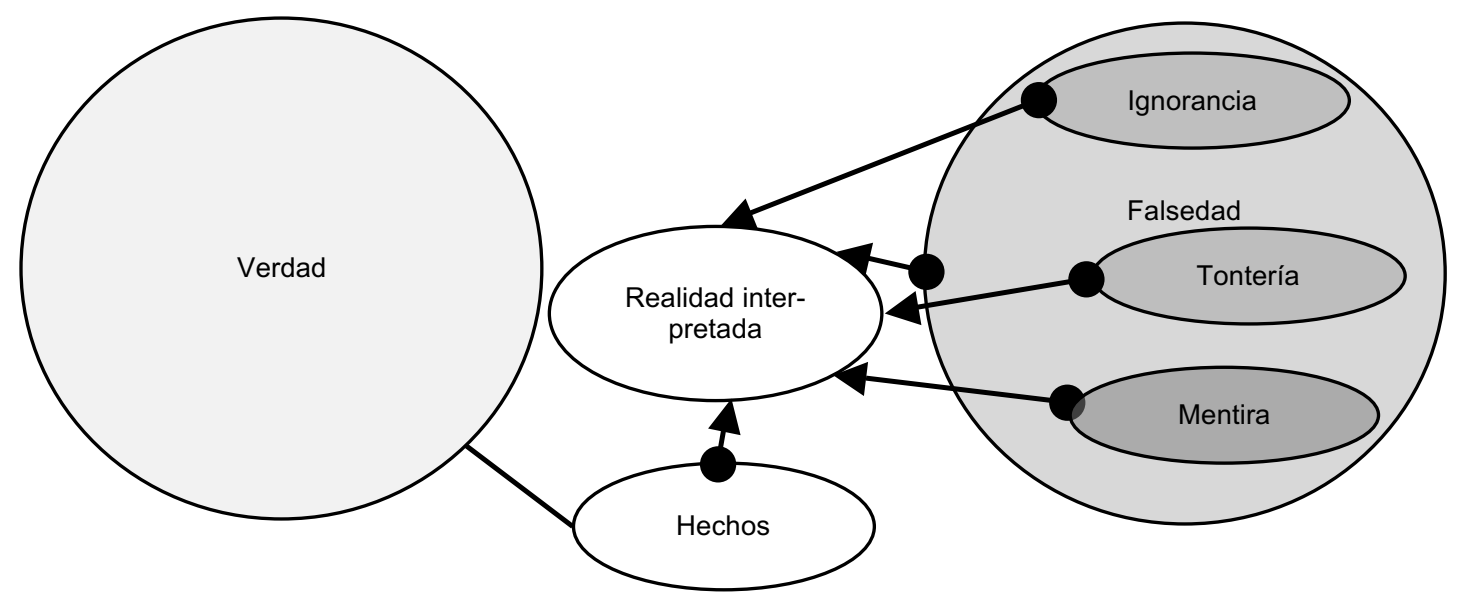

Figura 1. La verdad, la falsedad y la realidad interpretada.

Fuente: Elaboración propia.

Podemos interpretar la realidad a través de las falsedades o a través de la verdad, esta última es la única interpretación que tiene en cuenta los hechos, aspecto que las falsedades ignoran. El gradiente de responsabilidad moral se ha representado mediante la intensidad del color.

Con estas premisas McIntyre (2018) nos ofrece una definición de posverdad, dentro del ámbito de lo falso, y con elementos de algunos de los conceptos anteriormente mencionados: la posverdad es una falsedad tan indiferente a la verdad como lo es la tontería, y con una intención de manipulación propia de la mentira. Incluye, sin embargo, un elemento nuevo que prueba ir más allá de los límites conocidos actualmente por la falsedad: en lugar de funcionar en ausencia de la verdad, precisamente actúa en su presencia y con el objetivo de deslegitimarla (p.9). El método por el cual ejerce su influencia es la selección restrictiva de hechos y su interpretación intencionada. El alegato posverdadero no se refiere al abandono de los hechos, sino a una corrupción del proceso en el cual los hechos son subjetivamente seleccionados y usados con consistencia para manipular las creencias de la persona sobre la realidad (p.11). Se produce así en esta actividad una inversión entre lo falso y lo verdadero, y el receptor del mensaje posverdadero acaba creyendo en una perspectiva falsa, desconfiando de la verdad. 


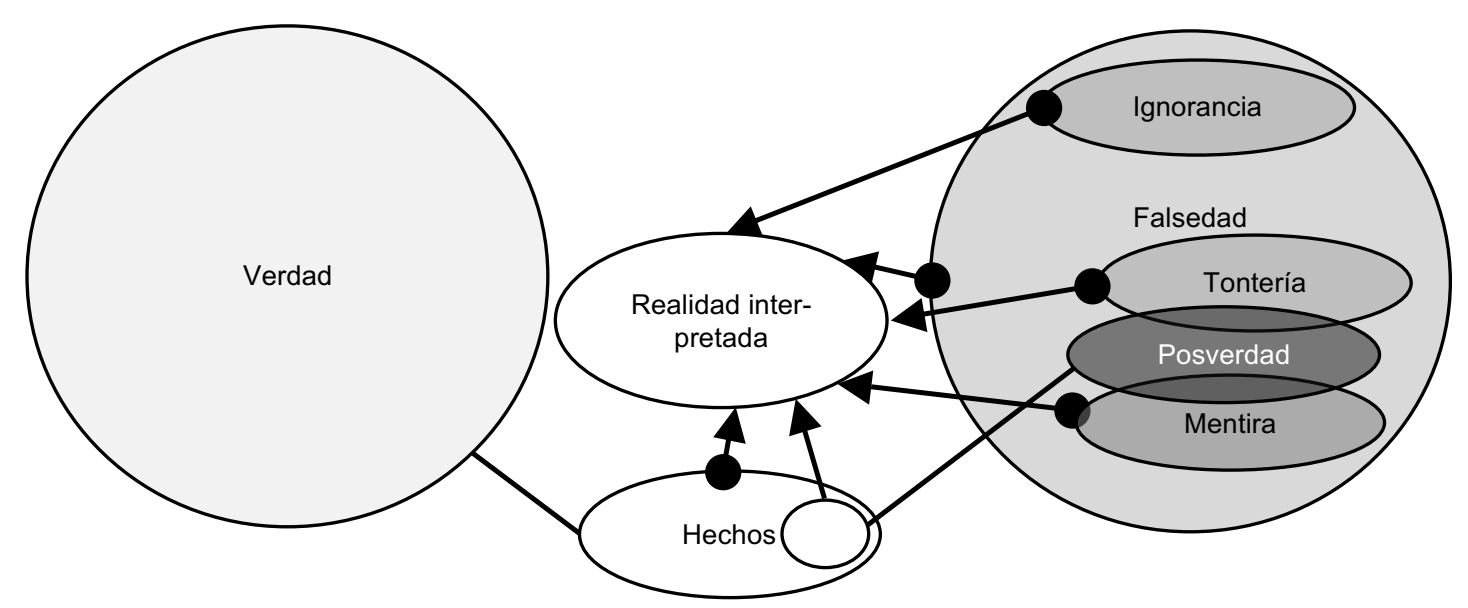

Figura 2. La verdad, la falsedad, la posverdad y la realidad interpretada.

Fuente: Elaboración propia.

En este nuevo esquema se incluye la posverdad y su relación, sesgada, con los hechos para definir la realidad interpretada.

¿Cuáles son las consecuencias que acarrean los discursos posverdaderos? Si la realidad y su interpretación es aquel espaciotemporal que incluye todo lo que consideramos verdadero, y excluye todo lo que consideramos falso, las lecturas posverdaderas de nuestras circunstancias invierten dicha relación de incluidos y excluidos, lo falso acaba definiendo la realidad y lo verdadero no. Entendiendo que el relato posverdadero se fundamenta en una sesgada e intencionada selección de hechos, acorde con las creencias, opiniones y prejuicios en los que se fundamenta; ejecuta un proceso que Mclntyre (2018) define como 'supremacía ideológica': concebir y entender la realidad desde un único tipo de ideología descartando la validez de otras. (p.13).

\subsection{Refutación y cohesión social a través de la verdad Nietzsche}

La definición de posverdad, extraída de las tesis de Mclntyre, depende exclusivamente de la aceptación de la verdad aristotélica. Debido a ello es relevante exponer una argumentación que quizás pueda refutar dicho postulado sobre lo veraz, y entender que implicaciones tendría. Una refutación tal puede ser encontrada en la filosofía de Nietzsche.

Si prestamos atención a los fragmentos póstumos de Nietzsche, escritos entre los años 1872-73 (Meca, 2010), descubrimos que concibe al ser humano como un animal en búsqueda constante de la verdad. Dicha idea se expresa en sus líneas a través de 
las palabras necesidad e impulso. El ser humano tiene un impulso y una necesidad de buscar la verdad, luego cualquier interpretación ficticia de la realidad será insuficiente. No obstante, el impulso y la necesidad de esta búsqueda no garantiza el éxito. Los resultados pueden seguir siendo meras ficciones, interpretaciones falsas que han sido tomadas como verdaderas y cuya ilusión se ignora (19 [43], p. 355). Esta sería la idea detrás de su concepto pathos de verdad, que por ende consistiría en la necesidad humana de construir un relato significativo sobre la realidad, y aceptarlo como verdadero, sea esa su correcta categoría ontológica o no (29 [4], p. 487).

Este es el punto de partida con el que Nietzsche elabora Sobre Verdad y Mentira en Sentido Extramoral. En ese discurso crítico sobre la finitud epistemológica humana, se acuña el origen de la idea de verdad al momento en el que se designa una relación singular y exclusiva entre palabras y cosas:

En este mismo momento se fija lo que a partir de entonces ha de ser «verdad», es decir, se ha inventado una designación de las cosas uniformemente válida y obligatoria, y el poder legislativo del lenguaje proporciona también las primeras leyes de verdad, pues aquí se origina por primera vez el contraste entre verdad y mentira. (Nietzsche, 1872/1996, p.20).

La unión de la palabra al objeto, al sujeto, al fenómeno, y un uso constante de ello, genera esta convención. Esto es, nuevamente, una verdad entendida como correlación, luego se entiende aquí que el punto de partida de Nietzsche y Mclntyre, la verdad como relación entre referencia y referente, es el mismo. Continuando la argumentación, la verdad se fundamenta con el uso: cuando la correlación se usa correctamente la sociedad la define como verdad, mientras que cuando se usa incorrectamente la define como falsa, pero cuando su incorrección es además intencionada, entonces hablamos de mentira, tal como Nietzsche lo expresa: "El mentiroso utiliza las legislaciones válidas, las palabras, para hacer aparecer lo irreal como real; dice, por ejemplo, "yo soy rico" cuando la designación correcta para su estado sería justamente «pobre»" (1872/1996, p. 20).

Esta última idea presenta una mayor profundización en la definición de verdad. Desde la filosofía nietzscheana, el uso inquebrantable de esta asociación acaba provocando el olvido de su arbitrariedad originaria. Nada justifica el nexo entre la referencia conceptual y la entidad referente.

¿Qué es una palabra? La reproducción en sonidos de un impulso nervioso. Pero inferir además a partir del impulso nervioso la existencia de una causa fuera de nosotros, es ya el resultado de un uso falso e injustificado del principio de razón (1872/1996, p. 21). 
En síntesis, la correlación de la verdad está totalmente injustificada. Dicho con un ejemplo, nada hay de montaña en la palabra "montaña", ni una pizca de tierra siquiera. La verdad se concluye como una ficción, pero una ficción acordada en sociedad, un contrato, un acuerdo establecido por todos donde consideramos, como en el ejemplo, que una elevación de tierra de más de 700 metros es una montaña. En consecuencia, si alguien señala al Mulhacén y dice: - es una montaña - todo bien, pero si dice: - no es más que una colina - está en un error, pues no sabe lo que una montaña es o, peor aún, lo sabe y nos está mintiendo. Este ejercicio humano de conexión es definido en Nietzsche como metáfora, dado que la metáfora es, según definición, un recurso lingüístico basado en la relación entre palabras y cosas. En su quehacer metafórico, los individuos realizan dos tipos de conexiones en tres ámbitos: primero los entes a sus imágenes mentales, y segundo tales imágenes a términos verbales. Según Nietzsche $(1872 / 1996$, p.22), es un proceso lleno de contradicciones, dado que encuentra una mera relación carente de causalidad. Lo subjetivo acaba definiéndose por la relación que un individuo establece entre términos y entes concretos, mientras que lo objetivo y veraz, es la mera concordancia entre todas las subjetividades de una sociedad.

Un constante uso de la metáfora no solo nos lleva a olvidar la inherente arbitrariedad de estas relaciones, sino que además nos exige agrupar las entidades en vocablos, guiándonos por un criterio de igualdad y representación, y produciendo la creación de conceptos. Nuevamente, Nietzsche encuentra más errores en este ejercicio, dada la nulidad de la representación al aceptar la natural desigualdad de las entidades artificialmente agrupadas:

Todo concepto se forma por equiparación de casos no iguales. Del mismo modo que es cierto que una hoja no es igual a otra, también es cierto que el concepto hoja se ha formado al abandonar de manera arbitraria esas diferencias individuales, al olvidar las notas distintivas, con lo cual se suscita entonces la representación, como si en la naturaleza hubiese algo separado de las hojas que fuese la «hoja», [...] ]una especie de arquetipo primigenio a partir del cual todas las hojas habrían sido tejidas, diseñadas, calibradas, coloreadas, onduladas, pintadas, pero por manos tan torpes, que ningún ejemplar resultase ser correcto y fidedigno como copia fiel del arquetipo (1872/1996, p. 23-24).

¿Podemos concluir que, desde la filosofía de Nietzsche, la verdad no existe? No exactamente. En Humano, Demasiado Humano, nuestro autor desarrolla en breves tesis sus postulados sobre la verdad. Nietzsche considera que las verdades fijas, inmutables y absolutas son refutables, y por ende es el momento de un tipo de verdad de carácter histórico, temporal. Al entender que el ejercicio gnoseológico humano está mediado por la sesgada capacidad de los instintos, estima que, incluso dejando de lado la expresión del conocimiento a través del lenguaje, la gnoseología humana es 
tan subjetiva que, ni posee un conocimiento de lo absoluto, ni posee un conocimiento de la verdad.

Pero entonces el filósofo percibe en el hombre actual «instintos» y supone que éstos forman parte de los datos inalterables del hombre y pueden, por tanto, ofrecer una clave para la comprensión del mundo en general6; toda la teleología está construida sobre el hecho de que se habla del hombre de los últimos cuatro milenios como de un hombre eterno al que todas las cosas del mundo están naturalmente orientadas desde un principio. Pero todo ha devenido; no hay datos eternos, lo mismo que no hay verdades absolutas (Nietzsche, 1878/2001, p.44).

En conclusión, tenemos un pathos humano de verdad que nos lleva a aplicar nuestro lenguaje a la realidad, por mor de entenderla, desde simples actos metafóricos hasta la creación de grandes conceptos basados no ya en las cosas en sí, sino en sus representaciones. Su constante uso social acaba definiendo una verdad arbitraria, injustificada y falsa. Esto es fruto de la incapacidad intelectual humana, al ser finita y al estar mediada por los instintos. A pesar de ello, esta argumentación presenta una pregunta, cuya respuesta es crucial en nuestra investigación sobre la problemática de la posverdad: ¿De dónde surge la necesidad humana de buscar la verdad, la premisa inicial de esta explicación? ¿Por qué tenemos un pathos de verdad?

Podemos responder a esta pregunta con una serie de argumentos secundarios en los textos de Nietzsche trabajados. El ejercicio metafórico y conceptual designado tiene una relevancia social: no se trata de un individuo relacionando palabras con cosas, ni palabras con representaciones agrupadas de cosas; sino de la sociedad construyendo tales relaciones, aceptando las creadas, rechazando y olvidando las que dejan de ser útiles o llegan a ser innecesarias. Es decir, siguiendo a Nietzsche (1872/1996), no encontramos razón para que el individuo en soledad necesite establecer una correlación entre palabras y cosas para entenderse con su realidad.

Pero, puesto que el hombre, tanto por la necesidad como por hastío, desea existir en sociedad y gregariamente, precisa de un tratado de paz y, de acuerdo con este, procura que, al menos, desaparezca de su mundo el más grande bellum omnium contra omnes. Este tratado de paz conlleva algo que promete ser el primer paso para la consecución de ese misterioso impulso hacia la verdad" (p.20).

Luego el pathos de verdad es en realidad el pathos social, el sentimiento de necesidad de rodearnos entre nosotros, de la inherente esencia social que nos determina, y que acaba promoviendo la creación del lenguaje, la correlación entre lenguaje y realidad, y finalmente, esa búsqueda de verdad. La función de la verdad queda determinada por establecer la comunicación de los miembros de la sociedad, gestionar su 
funcionamiento, permitir el trabajo y la organización en grandes grupos de personas, en suma asentar la civilización. Nietzsche defiende en este sentido que existen un cúmulo de ventajas en el uso de la verdad por parte de las sociedades humanas, de tal manera que tales agrupaciones no podrían desarrollarse sin dichos acuerdos del lenguaje.

Una tesis como esta, la verdad como desarrollo de un relato para la organización del ser humano en sociedad y civilización, es muy cercana a la elaborada recientemente por Yuval Noah Harari en su trabajo Homo Sapiens, idea que denomina 'Revolución cognitiva'. Según su trabajo investigativo en el marco de la prehistoria, el momento en el que el Homo Sapiens desarrollo la capacidad intelectual de crear ficciones sobre la manera de entender la realidad, fue el momento en el que tales ficciones permitieron a la humanidad cruzar el umbral de gestión y organización en grupo de más de 150 individuos. Considera que son estas ficciones culturales, fruto del nuevo desarrollo cognitivo, la posibilidad de creación de grandes sociedades que trabajan para un fin común:

¿Cómo es posible que los Homo Sapiens consiguieran cruzar el umbral y eventualmente fueran capaces de fundar ciudades que incluyeran diez mil habitantes o imperios que gobiernan cientos de millones? El secreto fue, probablemente, la aparición de la ficción. Un gran número de extraños pueden cooperar con éxito creyendo en mitos comunes. (Harari, La revolución cognitiva, la leyenda de Peugeot, párrafo 7, 2014).

Compartiendo desde meras relaciones lingüísticas hasta amplios conceptos de representaciones, los individuos en sociedad acaban adquiriendo convicciones de que sus correlaciones son la verdad del mundo que les rodea. Esta verdad se mantiene ante su facilidad, dado que siempre es más sencillo publicar aquel mensaje que defiende las convicciones establecidas, que el mensaje que las transgrede. Así las convicciones se convierten en la solidificación de las "verdades", y la resistencia ante nuevas descripciones que, accidentalmente, podrían ser más ciertas que las ya establecidas. Tal como Nietzsche dice, al final las convicciones son más enemigas de la verdad que las mentiras (Nietzsche, 1878/2001, p.235)

\section{RESULTADOS. LA VERDAD HISTÓRICA Y SOCIAL}

La perspectiva nietzscheana revela una nueva dificultad en la problemática de la verdad, la falsedad y la posverdad, que se plantea a través de los postulados de McIntyre. Partiendo de la similar concepción de verdad que usan tanto Nietzsche como Mclntyre, desde la cual el primero establece una refutación de la verdad, y el segundo profundiza en el campo de la falsedad hasta definir la posverdad, encontramos un nuevo esquema sobre las diferencias entre la verdad, la falsedad y sus conceptos internos. Bajo la argumentación nietzscheana, el campo de la verdad absoluta se ha 
convertido en el campo de la verdad histórica y social: un espacio de certezas temporales basadas en su concordancia con el común de la sociedad. En este sentido, la intención de desarrollar el relato más verdadero posible implica elaborar un explicación rigurosa, abarcando la mayor concordancia posible con los individuos, llegando a formular verdades más representativas, aceptables y duraderas. Es por ende, un área de investigación, donde podemos seguir trabajando por la verdad, aceptando su carácter parcial, lingüístico, correlativo, histórico, temporal y cambiante, pero siempre fundamento en nuestras evidencias, hechos, datos y conceptos que relacionamos a ello. En suma, un relato subjetivo con unas fuertes bases sólidas objetivas, una verdad basada en relaciones lingüístico-fenoménicas.

Por otro lado, en el campo de la falsedad, tendríamos el concepto de lo falso en sí, el de la ignorancia, la tontería, la mentira y ahora añadiríamos la posverdad. Tales conceptos, exceptuando lo posverdadero, funcionarían como lo han hecho hasta ahora: en ausencia de las auténticas relaciones establecidas entre el vocabulario y la realidad que rodea a sus hablantes. Lo posverdadero en cambio, funciona en presencia de tales relaciones y aun así ejerce el mismo efecto. Mientras que la verdad correlativa puede desarticular el relato de las otras falsedades, la posverdad se mantiene a flote y acabar estableciéndose como una nueva verdad correlativa. La verdad, como cemento de cohesión social, no es suficiente ante la posverdad, la cual podría defender cualquier cosa: desde una nueva cohesión social, hasta una disputa irremediable.

\section{DISCUSIONES Y CONCLUSIONES.}

En definitiva, el nuevo criterio de distinción entre la verdad histórica como marco de referencia ante lo posverdadero, consiste en su factor de cohesión común y social. Las verdades son relatos de la realidad forjados a través de la acumulación de diferentes perspectivas de mutuo acuerdo. Las posverdades en cambio son verdades forzadas, es decir, son interpretaciones de la realidad mucho más sesgadas, con más fundamento en las convicciones, sentimientos y emociones personales de tan solo un grupo de individuos. Generan supremacías ideológicas excluyentes en este sentido, utilizando recursos mediáticos masivos para hacer creer a su auditorio, el común de la sociedad, un nuevo tipo de verdad con la que no todos pueden estar de acuerdo, al ser mucho más sesgada que la verdad por correlación, esa que establecemos día a día entre todos. Su ejercicio por ello afectaría negativamente la convivencia humana.

Desde esta perspectiva, la problemática moral sobre el engaño se mantiene, a pesar de aceptar el carácter histórico de las verdades con las que se fundamenta la sociedad. La verdad, por muy certera o ambigua que pueda ser, sigue siendo una de las defensas fundamentales de la cohesión y convivencia humana. Los relatos verdaderos son postulados que permiten los acuerdos, la argumentación, el debate, 
las discusiones, los planteamientos, la planificación en grupo, etc. Sigue siendo importante denunciar las agresiones de las falsedades, no por la garantía absoluta que pudiera tener la verdad, sino más bien por la cohesión que una verdad común representa. Al mismo tiempo, la temporalidad de la verdad implica la necesidad constante de la investigación y reflexión del conocimiento científico, debemos seguir preguntándonos cuál es la verdad y cómo podemos encontrarla. De esta manera, la denuncia ante las noticias falsas, los bulos y las mentiras, puede justificarse no ante un criterio de verdad absoluto como única manera aceptable y fija de entender la realidad, sino ante un criterio de verdad histórica social e incluyente. Ante una argumentación que defienda la narración posverdadera, sería plausible rebatir el aspecto democrático de la versión verdadera, pese a ser posiblemente refutable.

En este último aspecto, sería importante reseñar la lectura Bruno Borge (2016) sobre Lakatos, en el tema de investigación científica y verdad. Para Lakatos, la indagación científica también implica un carácter temporal en la verdad, particularmente por el falibilismo de la formulación de leyes naturales, basadas en futuras observaciones que refuten su contenido. Sin embargo, señala que podemos aceptar un optimismo epistemológico, una visión positiva de nuestra incapacidad para alcanzar la verdad absoluta. Las leyes naturales son consideradas como leyes de enunciado infinito, ya que rigen una infinidad de eventos posibles en la realidad, mientras que las elaboradas por la ciencia son de enunciado finito, pertenecen al conocer y al lenguaje humano. El perfeccionamiento del enunciado de tales leyes implica un acercamiento progresivo a la verdad, luego esta se entiende como un horizonte y la investigación como un constante caminar hacia ella. En este sentido, la validez de las indagaciones científicas también queda restringida a una idea de verdad parcial, que al mismo tiempo es distinguible de cualquier concepto de falsedad.

Ciertas cuestiones pueden surgir en base a esta conclusión: por ejemplo, considerando que el valor de la verdad se basa en la cohesión social, ¿Sería moralmente más correcto defender un relato posverdadero más incluyente? ¿Es el carácter de acuerdo social el único criterio para distinguir entre verdad y falsedad en nuestra relación diaria con el mundo? La posverdad, una vez establecida e interiorizada por la sociedad, formando parte de su construcción lingüísticofenoménica, ¿podría llegar a ser una nueva verdad correlativa con todas sus garantías, diferenciándose únicamente en que ha nacido de presupuestos personales e ideológicos? ¿Qué pasaría si, tras encontrar la verdad absoluta en nuestra investigación sobre el conocimiento, descubriéramos que su relato es fuente de división social? Estos son aspectos que preocupan y que podrían desencadenar análisis nuevos y más profundos. 


\section{Referencias}

BBC News (2016) 'Post-truth' declared word of the year by Oxford Dictionaries. Recuperado de: https://bbc.in/2Jfm0Gh

Borge, Bruno. (2017). Truth and laws of nature in the methodology of scientific research programs. Signos filosóficos, 19(37), 146-169. Recuperado de: https://bit.ly/2WFpQvo

Harari, Yuval Noah. (2014). Homo Sapiens: a brief history of mankind. Canada, Signal Books. V.31. Kindle.

Higgins, K. (2016). Post-truth: A guide for the perplexed. Nature, 540(7631), 9. Recuperado de: https://bit.ly/2JAH7SG

McIntyre, L. (2018). Postruth. Londres, Reino Unido: Massachusetts Institute of Technology.

Nietzsche, F. (18721996). Sobre Verdad y Mentira en Sentido Extramoral. Madrid: Tecnos.

Nietzsche, F. (1878/2001). Humano, demasiado Humano. Volumen I. Madrid, España: Akal.

Oxford (2016), Definición de Posverdad en el diccionario online. Recuperado de: https://bit.ly/2gP7aYv

Sánchez Meca, D. (2010). Friedrich Nietzsche. Fragmentos Póstumos. Volumen I. Madrid, España: Tecnos.

Sepczynska, D. (2019). Post-truth from the perspective of Hannah Arendt's political theory. Filozofia, 74(3), 209-222. doi:10.31577/filozofia.2019.74.3.4

Van Parijs, P. (2018). What place (if any) for academics in our post-truth era? Ethical Perspectives, 25(1), 143-148. doi:10.2143/EP.25.1.3284676 